\title{
Selective Binding of pVTK Peptide- and Bisphosphonate-Functionalized Micelles to Prostate Cancer Cells, Osteoblasts, and Osteoclasts
}

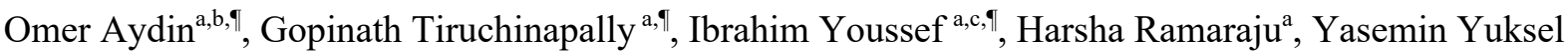
Durmaz $^{\mathrm{a}, \mathrm{d}}$, Kenneth M. Kozloff ${ }^{\mathrm{a}, \mathrm{e}}$, David H. Kohn ${ }^{\mathrm{a}, \mathrm{f}}$, and Mohamed E. H. ElSayed ${ }^{\mathrm{a}, \mathrm{g}}$ *

${ }^{a}$ University of Michigan, Department of Biomedical Engineering, Ann Arbor, MI, 48109, USA

${ }^{b}$ Erciyes University, Department of Biomedical Engineering, Talas, Kayseri, 38039, Turkey

${ }^{c}$ Mansoura University, Department of Chemistry, Mansoura ET-35516, Egypt

${ }^{d}$ Istanbul Medipol University, Department of Biomedical Engineering, Beykoz, Istanbul 34810, Turkey

${ }^{e}$ University of Michigan, Department of Orthopaedic Surgery, Ann Arbor, MI, 48109, USA

${ }^{f}$ University of Michigan, Department of Biologic and Material Sciences, Ann Arbor, MI, 48109, USA

${ }^{g}$ University of Michigan, Macromolecular Science and Engineering Program, Ann Arbor, MI, 48109, USA

"These authors contributed equally to this work.

Submitted: January 9, 2022

\section{Graphical abstract}

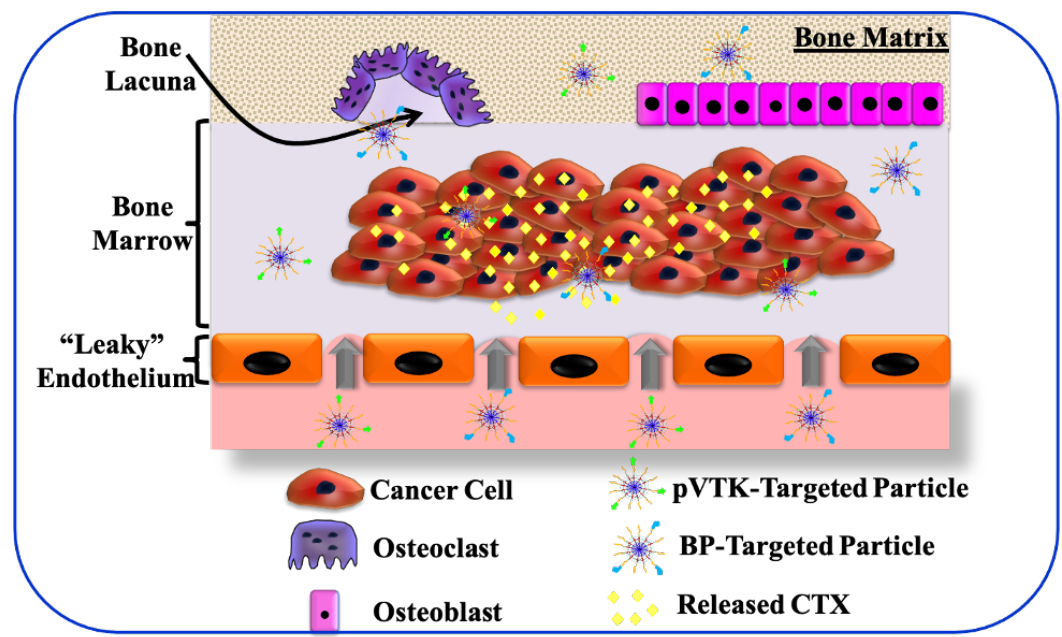

\section{Abstract}

This report describes the development of functionalized polymeric micelles encapsulating a chemotherapeutic agent. The results indicate the ability to achieve selective uptake into different cell populations in metastatic prostate cancer in vitro by appropriate selection of the targeting ligand. This paves the way for administering single or multiple therapeutic agents into bone metastases. These particles are functionalized to display the pVTK peptide of bisphosphonate (BP) as two different targeting ligands to assess their ability to trigger selective binding and internalization into prostate cancer cells, osteoblasts, osteoclasts, and macrophages in vitro. These bone-targeting particles (60-90 $\mathrm{nm}$ ) bind to hydroxyapatite/bone powder with high affinity. Uptake of pVTK- and BP-conjugated particles into prostate cancer cells (PC-3 and C4-2B), MC3T3, RAW264.7 bone macrophages, and RANKL-activated RAW264.7 cells cultured on a regular tissue culture plate and bone-like surface

* Corresponding Author: Mohamed E.H. ElSayed, Ph.D., University of Michigan, Department of Biomedical Engineering, 1101 Beal Avenue, 2150 Lurie Biomedical Engineering Building, Ann Arbor, MI 48109, USA. E-mail: mohamedus36@gmail.com (M.E.H. ElSayed is a member of the Editorial Board of Precision Nanomedicine.) 
was investigated. Results show that increasing the number of BP-targeting ligands displayed on particle surface shows 60-fold higher affinity to RAW 264.7 macrophages seeded on conventional tissue culture plates than non-conjugated particles. In addition, the uptake study results show that pVTKfunctionalized particles were selectively internalized by $\mathrm{C} 4-2 \mathrm{~B}$ and $\mathrm{MC} 3 \mathrm{~T} 3$ osteoblast cells cultured on BLS, whereas BP-functionalized particles are selectively internalized by PC-3 and RAW264.7 macrophage cells cultured on BLS. Therefore, efficient and selective bone-conjugated therapies are needed to kill cancer cells and inhibit the crosstalk with other cells in the metastatic lesion, resulting in osteoblastic, osteolytic, or a mixed phenotype.

\section{Keywords:}

Bone-targeting particles, $\mathrm{pVTK}$ peptide, bisphosphonates, $\mathrm{pH}$-sensitive micelles, Cabazitaxel

\section{Rationale and Purpose:}

Reports have shown that selective delivery of cytotoxic agents to metastatic prostate cancer is critical for enhanced efficacy and safety. Therefore, we focus on identification and in vitro characterization of targeting ligands that can mediate cell-specific internalization into different cell types in metastatic cancer lesions.

\section{Introduction}

In the US, nearly 1 out of every 7 men is diagnosed with prostate cancer resulting in 1 out of 39 men dying [1]. Tremendous advances in the detection and treatment of primary prostate cancer, especially widespread use of prostate-specific antigen screening over the past four decades, have led to a significant increase in the 5-year survival rate for local prostate cancer, which is now almost $100 \%$ [1]. However, despite the impressive survival rate for patients diagnosed with prostate cancer localized to the gland, only $27 \%$ of patients diagnosed with metastatic disease survive for more than 5 years [2]. Autopsy of patients dying of prostate cancer shows that $90 \%$ of the cases ha metastatic disease, and bone is the primary site of metastases $[3,4]$.

The bone microenvironment provides a shield against chemotherapeutic agents and is a fertile ground for cancer cells to proliferate in a process named the "Seed and Soil" mechanism $[5,6]$. Metastasizing cancer cells establish crosstalk with osteoblasts (bone-forming cells) and osteoclasts (bone degrading cells) which controls bone turnover in these lesions and the phenotype of the disease (i.e., osteoblastic vs. osteolytic) [7]. In metastatic prostate cancer lesions in bone, osteoclasts activity causes localized degradation of the bone matrix resulting in a sharp drop in the microenvironment $\mathrm{pH}$ down to 4.5 [8] and a localized increase in $\mathrm{Ca}^{2+}$ concentration plus multiple growth factors including transforming growth factor- $\beta$ (TGF- $\beta$ ) and insulin-like growth factor (IGF), which promote the growth and proliferation of prostate cancer cells [9].
The high local concentration of TGF- $\beta$ and IGF, directly and indirectly, activate osteoblasts to deposit new matrix at the resorption sites forming a crystallized woven bone that is mechanically inferior to natural bone $[10,11]$. The activity of osteoclasts and osteoblasts in metastatic cancer lesions in bone establishes a vicious cycle that challenges current treatment strategies and controls whether cancer lesions will exhibit an osteolytic, osteoblastic, or mixed phenotype [12].

Degradation of the bone surface by osteoclasts activity and deposition of woven bone by osteoblasts results in exposure of the bone's hydroxyapatite surface and presentation of $\mathrm{Ca}^{2+}$ ions that imparts a high positive charge density to bone surface in metastatic cancer lesions in bone [13, 14]. Given the limited ability of chemotherapeutic agents to achieve an effective cytotoxic concentration in the metastatic lesions in bone, we aim to utilize a combination of the tumor's leaky vasculature and the unique bone surface properties to target cancer lesions using micelles as conjugated nanoparticles and deliver chemotherapeutic agent/s. Specifically, we utilize an amphiphilic triblock copolymer composed of a hydrophobic poly(methyl methacrylate) (PMMA), a central poly(acrylic acid) (PAA) block, and a hydrophilic poly(ethylene glycol) (PEG) block to self-assemble, forming polymeric micelles [15]. The core of these micelles encapsulates a chemotherapeutic agent (Cabazitaxel, CTX) and is stabilized by an acid-sensitive crosslinker that reacts with the central PAA block and "stitch" the polymer chains together to 
prevent the non-specific release of the loaded cargo $[15,16]$.

One clinically preferred therapeutic for metastatic bone cancer is bisphosphonates (BPs). pamidronate, risedronate, alendronate, and zoledronate are common BPs in the market containing nitrogen atom $/ \mathrm{s}$ in their structures. The specific orientation and location of the nitrogen atom $/ \mathrm{s}$ in their structural backbone makes these BPs extremely potent and constitute a "pharmacophore" [17, 18]. Zoledronate is the most potent of all BPs because of the contribution of nitrogen content and hydrophobic binding pocket of imidazole $[19,20]$. The literature shows that, at the molecular level, BPs inhibits the enzyme farnesyl pyrophosphate synthase (FPPS), leading to knockdown of prenylation of small GTPases like Rac, Ras, or Rab, which have a role in cholesterol synthesis, cytoskeletal organization, bone resorption, and cell morphology [21]. Inhibition of prenylation reduces osteoclast activity and triggers apoptosis [22, 23]. Because of these pharmacological effects, BPs reduce the resorptive capability of osteoclasts. In addition to the role of antiresorptive BPs, they have direct functions such as antitumor [24], antiangiogenic [25], and anti-migratory [26] effects. Further, BPs are co-administered with doxorubicin, docetaxel, and paclitaxel [27-31] as cocktail therapies to treat bone metastasis. BPs are FDA-approved against osteoporosis, $\mathrm{P}$
Paget's disease, pediatric bone diseases [32], multiple myeloma, breast cancer metastasis, or prostate cancer to bone [33] as an adjuvant therapy to prevent metastatic bone pain. BPs also lower the risk of broken bones because they have potent inhibitor functions on osteoclast-mediated bone resorption via binding to the bone mineral and then are taken up by osteoclasts through fluid-phase endocytosis from the acidified bone surface during osteolytic resorption [34].

Neither cancer chemotherapy nor BP-based cancer therapies demonstrate the desired level of therapeutic activity in regressing tumor progression or increasing the lifespan of bone metastasized patients [35]. These therapies have limitations such as environment-mediated drug resistance in bone metastasis in the presence of various cytokines and growth factors [36] and not being able to achieve the desired drug concentration in the bone because of the lack of bone targetability. Due to drug resistance and inefficient chemotherapy concentration in metastasized bone, a higher concentration of chemotherapy is employed, leading to non-specific systemic side effects [37]. These limitations may be addressed by targeted delivery to cancer lesions and specific cells in the metastatic bone [38-40]. For example, PC-3 prostate cancer is a known osteolytic character [41, 42], whereas C4-2B prostate cancer is in a mixed form of osteolytic and osteoblastic $[43,44]$.

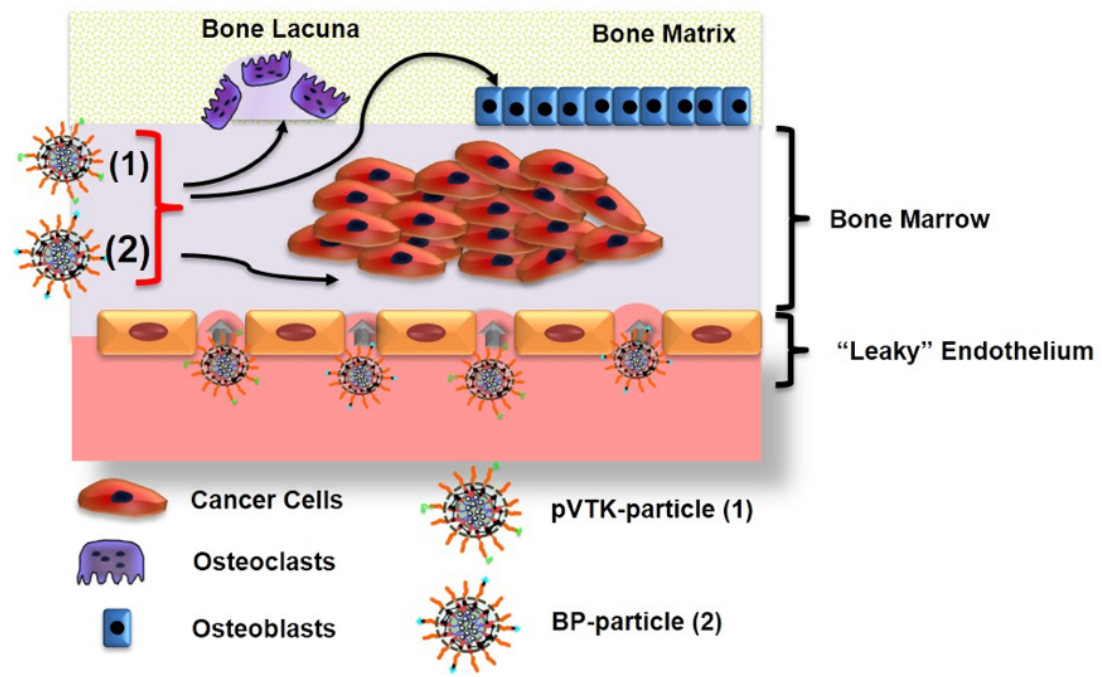

Figure 1. The hypothesized M-pVTK and M-BP nanomedicine-based therapies to modulate cancer cells in the bone microenvironment. 


\section{Experimental design}

To achieve preferential homing of these particles into prostate cancer lesions in bone and trigger selective uptake into prostate cancer cells, we evaluated two different ligands that can recognize and bind to the rough and cationic bone surface, $a$ bisphosphonate (BP) and a 12-membered peptide.
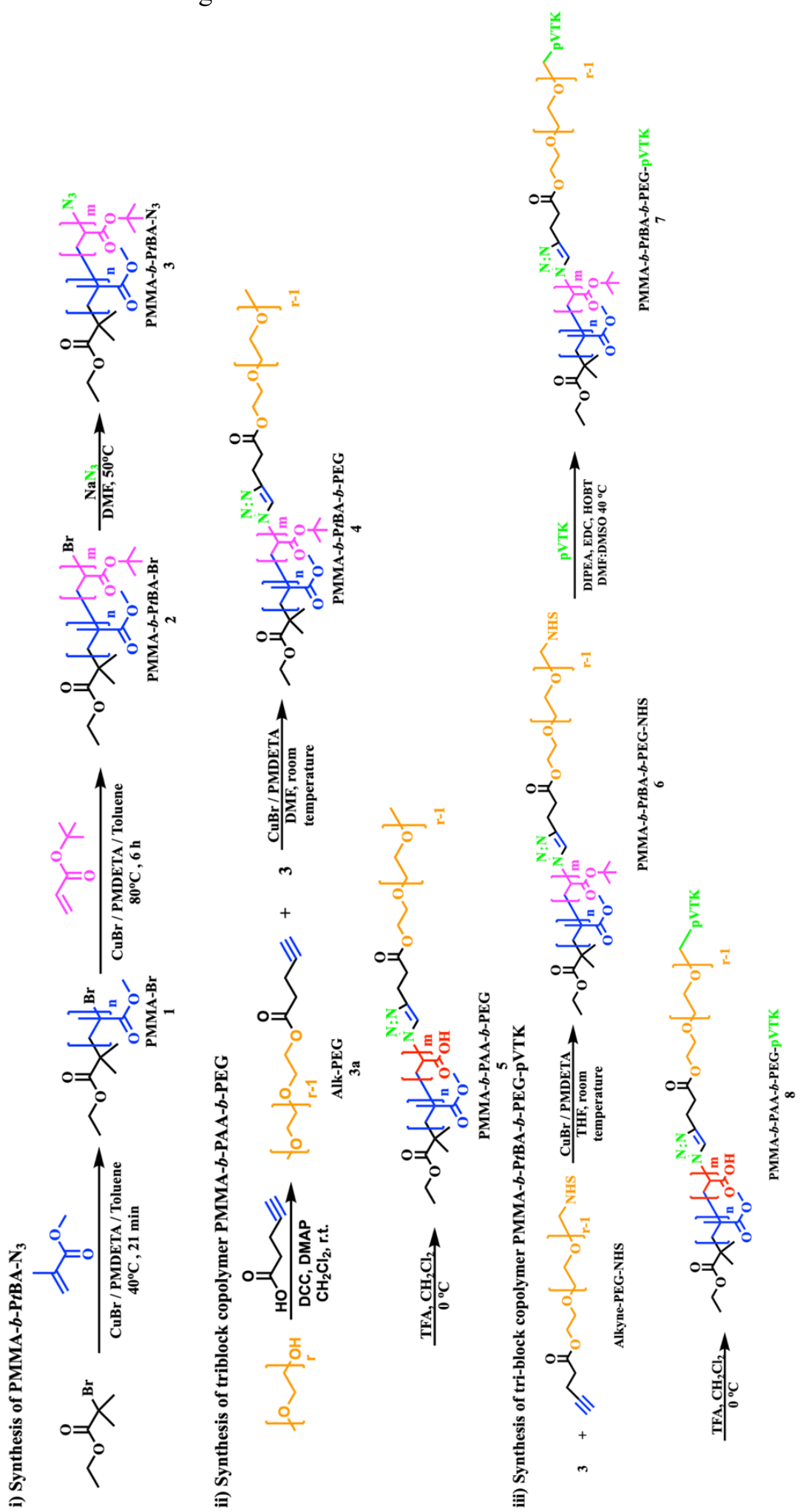

Figure 2A. A schematic drawing showing i) scheme for synthesis of PMMA-b-PtBA-N $N_{3}$ copolymer, ii) PMMA-b-PAA-b$P E G$, and iii) PMMA-b-PAA-b-PEG-pVTK 


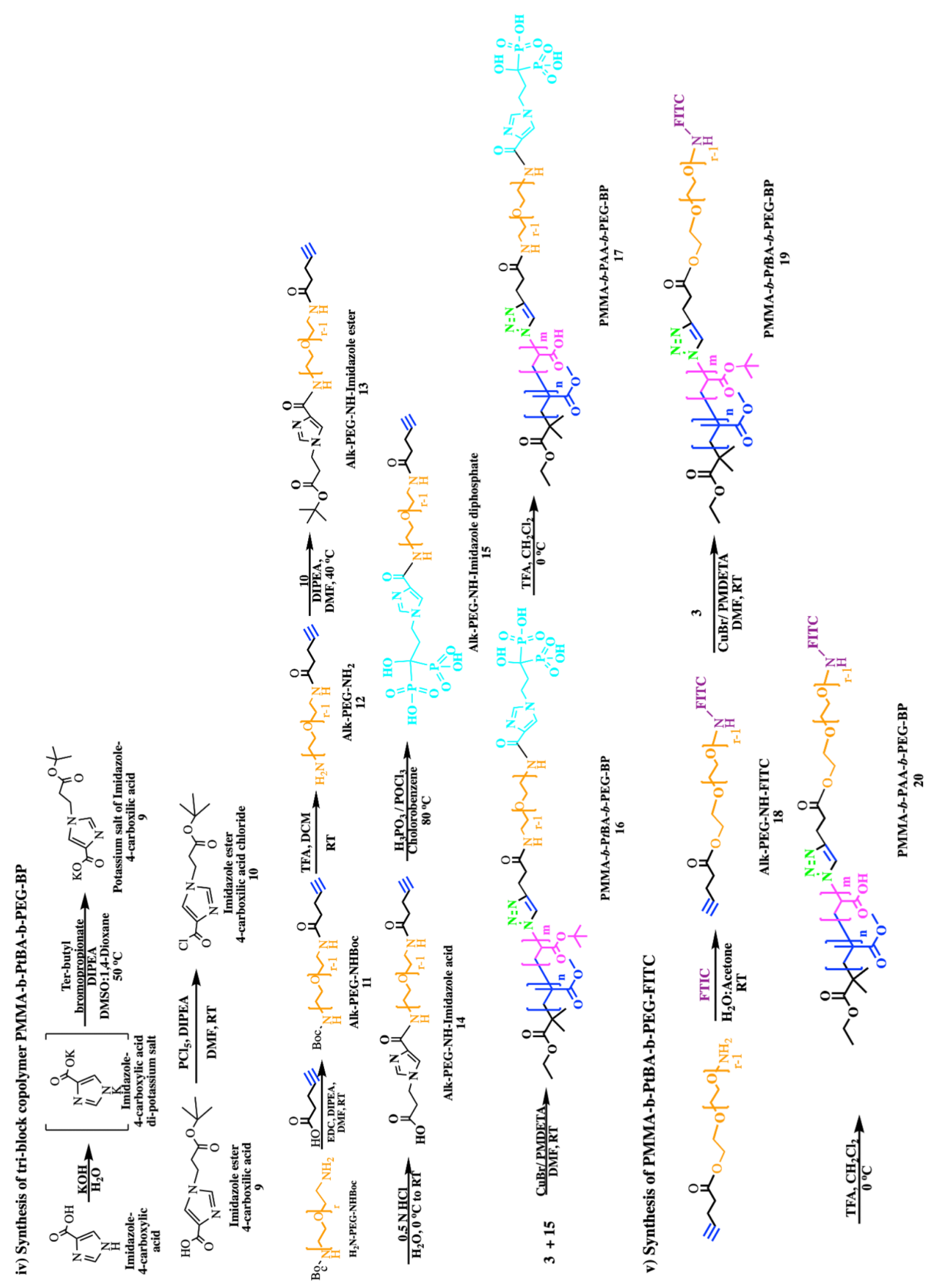

Figure 2B. A schematic drawing showing a scheme for the synthesis of (iv) PMMA-b-PAA-b-PEG-BP and of (v) PMMA-b$P A A-b-P E G-F I T C$.

We synthesized a zoledronic acid (ZA) analog that allows covalent coupling to primary amine at one end of the PEG block without sterically interfering with the phosphonate groups at another end of the PEG (Figure 2). The first ligand is based on ZA, a potent bisphosphonate (BP) that has been shown to efficiently distribute to the bone and suppress osteoclasts' 
activity. The second ligand is a 12-membered peptide (VTKHLNQISQSY) phosphorylated at the serine residue and named pVTK. This pVTK peptide is conjugated via a peptide bond to PEG brush displayed on the surface of the micelle to utilize its ability to strongly bind to hydroxyapatite surfaces and achieve selective binding to actively mineralizing the bone surface in metastatic cancer lesions in bone[4548]

We synthesized a ZA analog that allows covalent coupling to primary amine at one end of the PEG block without sterically interfering with the phosphonate groups at another end of the PEG (Figure 2).

Detailed synthesis protocols and spectral data can be found in the supplementary file. The phosphonate groups have been shown to mediate binding to exposed osteolytic bone pits in cancer lesions via electrostatic interaction resulting in selective uptake by osteoclasts via fluid-phase endocytosis osteolytic resorption $[34,49]$. We investigated the ability of both BPand pVTK-conjugated particles to bind to bonelike surfaces as a function of ligand density. Further, we evaluated the binding and internalization of BP- and pVTK-conjugated particles into $\mathrm{PC}-3$ and $\mathrm{C} 4-2 \mathrm{~B}$ prostate cancer cells, MC3T3 pre-osteoblasts, RAW 264.7 macrophages, and activated RAW 264.7 osteoclast cells in comparison to non- conjugated particles. The main aim of this study is to investigate the internalization of boneconjugated particles into the various tumor and bone cells through BLS and whether different cells in the metastatic lesions can discriminate between different targeting ligands, which will enable cell-specific uptake of therapeutic agents.

\section{Materials and methods \\ Formulation and characterization of FITC-labeled pVTK- and BP-conjugated micelles}

We prepared different micelles that display a combination of FITC, pVTK, and BP on the free ends of the PEG brush at different molar ratios following our previously published methods[15]. These micelles were crosslinked using a $\mathrm{pH}$-sensitive linker (2,2'-(Propane-2,2diylbis(oxy))-diethanamine), which undergoes fragmentation and intracellular release of loaded cargo upon internalization into the endosomes. Briefly, non-conjugated PMMA- $b$ PAA- $b$-PEG polymer was used as the main component of the micelles composition while varying the molar ratio of PMMA- $b$-PAA- $b$ PEG-FITC, PMMA- $b$-PAA- $b$-PEG-pVTK, and PMMA- $b$-PAA- $b$-PEG-BP to prepare FITClabeled and/or pVTK- and BP-conjugated micelles, respectively (Figure 3 ).

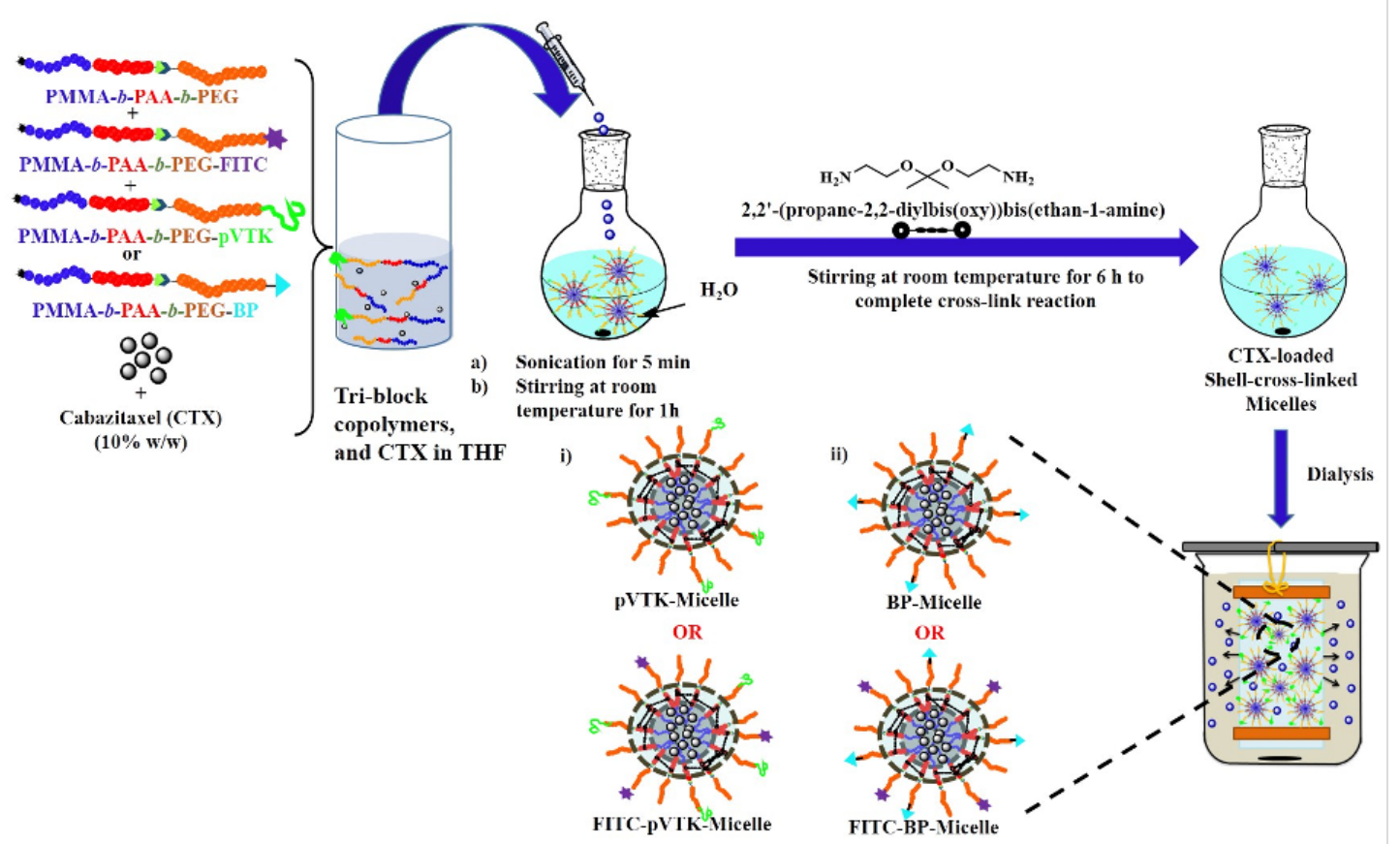

Figure 3. A schematic drawing of the formulation of PMMA-b-PAA-b-PEG tri-block copolymer into micelles i) M-pVTK or FITC tagged FITC-pVTK-Micelle and ii) M-BP or FITC-BP-Micelle. 
We prepared $\mathrm{pVTK}$-conjugated micelles with

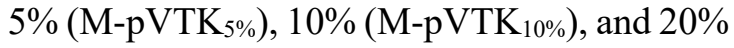
$\left(\mathrm{M}-\mathrm{pVTK} \mathrm{T}_{20}\right.$ ) pVTK targeting ligands by varying the amount of the PMMA- $b$-PAA- $b$ PEG-pVTK polymer incorporated in micelles composition. Similarly, we prepared BPconjugated micelles with 5\% (M-BP $\left.{ }_{5 \%}\right), 10 \%$ $\left(\mathrm{M}-\mathrm{BP}_{10 \%}\right)$, and $20 \%\left(\mathrm{M}-\mathrm{BP}_{20 \%}\right) \mathrm{BP}$ targeting ligands by varying the amount of the PMMA$b$-PAA- $b$-PEG-BP polymer incorporated in micelles composition.

Encapsulation of cabazitaxel into different micelles was carried out by following our previously published protocol $[15,16]$ to prepare CTX-loaded micelles. CTX content in different formulations was determined by dissolving $1 \mathrm{mg}$ of the lyophilized product in 10 $\mathrm{mL}$ of THF, extracting the encapsulated CTX, and determining its concentration. A CTX calibration curve $(0-300 \mu \mathrm{M})$ was used (RPHPLC) to calculate CTX encapsulation efficiency and loading content following our published protocol[15]. The size and zeta potential of all micelle formulations were measured using a 90Plus particle size analyzer with ZetaPALS capability (Brookhaven Instruments Corporation, Holtsville, NY) at $25^{\circ} \mathrm{C}$ following established protocols[50]. Results are presented as the mean of three replicates \pm standard error of the mean (SEM).

\section{Binding of pVTK- and BP-conjugated}

\section{micelles to bone/HA powder}

We measured the binding ability of pVTKand BP-conjugated micelles to granulated rat bone/HA powder and compared it to nonconjugated micelles. Rat bone powder was prepared following a published protocol [51]. Fore and hind limbs were dissected free from soft tissue followed by flushing the bone marrow, bone defatting (i.e., incubation in $\mathrm{CHCl}_{3} / \mathrm{MeOH}$ for $4 \mathrm{~h}$ then $100 \% \mathrm{EtOH}$ for $1 \mathrm{~h}$ ), bone drying overnight at $37^{\circ} \mathrm{C}$, homogenization using a cryomill at $-150{ }^{\circ} \mathrm{C}$, and sieving to separate bone granules with an average diameter between $42 \mu \mathrm{m}$ and $295 \mu \mathrm{m}$. We incorporated a $4 \%$ molar ratio of PMMA- $b$ PAA- $b$-PEG-FITC in conjugated and nonconjugated micelles to allow quantitative assessment of micelles binding to different surfaces based on the intensity of the bound fluorescence signal. Briefly, FITC-labeled micelles were dissolved in Trizma buffer (50
$\mathrm{mM}$ ) at a concentration of $1 \mathrm{mg} / \mathrm{mL}$ before incubating $100 \mu \mathrm{L}$ of the micelle solution with $50 \mu \mathrm{L}$ of bone powder solution $(10 \mathrm{mg} / \mathrm{mL})$ for $3 \mathrm{~h}$ followed by filtration of this mixture through a $0.65 \mu \mathrm{m}$ hydrophilic, low protein binding 96-well filter plate (MultiScreen ${ }^{\circledR}$, Millipore) by centrifugation at 2,095 $\mathrm{g}$ for 10 $\mathrm{min}$. The initial fluorescence intensity and that of the filtrate solutions were measured at $\lambda_{\mathrm{ex}}$ $490 \mathrm{~nm}$ and $\lambda_{\text {em }} 520 \mathrm{~nm}$ using a Fluoroskan plate reader to determine the fraction of the particles bound to the bone surface. The volume-adjusted fluorescence difference for each micelle formulation before and after mixing with the bone powder was normalized to the initial fluorescence intensity of the micelle solution in the absence of bone/HA powder to calculate binding rates. The ability of free pVTK peptide and pVTK- and BPconjugated micelles binding to $\mathrm{HA}$ and bone powders was quantified following our previously published methods [46, 52, 53]. Results are presented as the mean of three replicates \pm SEM.

\section{Cell Culture}

PC-3 and C4-2B cells were cultured following published protocols[54]. Briefly, PC-3 and C42B cells were cultured in RPMI-1640. Culture media for both cell lines was supplemented with $10 \%$ fetal bovine serum (Gibco, Carlsbad, CA) and $1 \%$ antibiotic-antimycotic solution (Gibco, Carlsbad, CA). MC3T3 and RAW 264.7 cell lines were also cultured following a published protocol [53]. Briefly, to differentiate RAW 264.7 cells to osteoclast, mouse recombinant RANKL (Sigma R0525, St. Louis) was added to the culture medium for 4-5 days at a final concentration of $50 \mathrm{ng} / \mathrm{mL}$ following published protocols [55]. All cell lines were incubated at $37^{\circ} \mathrm{C}$ and $5 \% \mathrm{CO}_{2}$ while changing the culture medium every other day and passaging the cells using $0.05 \%$ Trypsin-EDTA solution after reaching $80 \%$ confluence except RAW 264.7 cells, which required a cell stripper to detach the cells from the plate surface.

\section{Cellular uptake studies}

Uptake of different micelle formulations into PC-3, C4-2B, MC3T3, and RAW 264.7 cells was investigated after culturing on conventional tissue culture plates and bone-like surfaces (BLS). For uptake studies in standard cell culture plates, PC-3, C4-2B, MC3T3, and RAW 264.7 cells were seeded in 24 -well plates 
at a seeding density of $2 \times 10^{5}$ cells/well and allowed to adhere for $24 \mathrm{~h}$ before incubating with FITC-labeled M-pVTK $10 \%, \mathrm{M}_{-\mathrm{BP}}(0 \%, 5 \%$, $10 \%$, and $20 \%$ ligands, and non-conjugated micelles at $40 \mu \mathrm{g} / \mathrm{mL}$ for $3 \mathrm{~h}$. The treated cells were washed twice with phosphate-buffered saline (PBS) $(500 \mu \mathrm{L})$ before being trypsinized with $0.05 \%$ trypsin-EDTA solution, except for RAW 264.7 cells were detached from the plate surface using a cotton swab. This was followed by centrifugation at $1,000 \mathrm{rpm}$ for $5 \mathrm{~min}$ to collect the cell pellets, suspended in PBS $(1 \mathrm{~mL})$, and analyzed using flow cytometry CyAn ${ }^{\mathrm{TM}}$ ADP Analyzer (Beckman Coulter, Brea, CA) for FITC fluorescence signal.

PC-3, C4-2B, MC3T3, and RAW 264.7 cells were seeded on BLS at a seeding density of 2 $\times 10^{5}$ cells/well and allowed to adhere for $24 \mathrm{~h}$. RAW 264.7 cells were treated with RANKL (50 $\mathrm{ng} / \mathrm{mL}$ ) for 4 days by changing the medium/RANKL every 2 days before initiating the uptake study. RAW 264.7 cells were continuously treated with RANKL during the uptake study. FITC-labeled pVTK- and BPconjugated and non-conjugated micelles in OPTI-MEM medium were added to different cells $24 \mathrm{~h}$ after their seeding and incubated for $3 \mathrm{~h}$. Cell harvesting and assessment of FITC fluorescence signal using flow cytometry were analyzed following the same method described earlier. Results are presented as the mean of three replicates \pm SEM.

\section{Cytotoxic activity of CTX-loaded micelles}

We investigated the cytotoxic activity of CTX-loaded micelles against PC-3, C4-2B, MC3T3, RAW 264.7, and activated RAW 264.7 cell lines cultured on BLS and compared to equal concentrations of free CTX. Briefly, PC-3, C4-2B, MC3T3, RAW 264.7, and activated RAW 264.7 cells were seeded on BLS discus placed in 24-well plates at a seeding density of 60,000 cells/well and allowed to adhere for $24 \mathrm{~h}$. Free CTX and CTX-loaded M$\mathrm{pVTK}_{10 \%}, \mathrm{M}-\mathrm{BP}_{20 \%}$, and non-conjugated micelles were added to cultured cells at $0.1,1$, and $10 \mathrm{nM}$ equivalent CTX concentrations at a final volume of $500 \mu \mathrm{L}$ of the culture medium followed by incubation for $48 \mathrm{~h}$. At the end of the incubation period, the culture medium was aspirated, cultured cells were washed with PBS, followed by incubation with $500 \mu \mathrm{L}$ of Resazurin Dye at a dilution of $1 / 13$ in the OPTIMEM medium for 3-4 $\mathrm{h}$ before measuring solution fluorescence $\left(\lambda_{\mathrm{ex}}=570 \mathrm{~nm}, \lambda_{\mathrm{em}}=590\right.$ $\mathrm{nm}$ ) using the Fluoroskan Ascent FL plate reader. Fluorescence values were normalized to the value observed with similar culturing of different cell lines in a regular culture medium (control group) to calculate the percentage of viable cells remaining after incubating different micelles. Results are presented as the mean of three replicates \pm SEM.

\section{Results and Discussion}

\section{Micelle formulation and characterization}

The development of micelle formulation with well-defined characteristics is contingent upon the successful synthesis of the polymeric building blocks. The Supplementary Information provides detailed spectral analysis of the synthesized PMMA- $b$-PAA- $b$-PEG, PMMA- $b$-PAA- $b$-PEG-pVTK, PMMA- $b-$ PAA- $b$-PEG-BP, PMMA- $b$-PAA- $b$-PEG-FITC polymers confirming their successful synthesis and exact composition. These polymers were used to formulate FITC-labeled pVTK- and $\mathrm{BP}-$ conjugated and non-conjugated micelles.

Results show that non-conjugated micelles $(0$ mole $\%$ of targeting ligands) exhibited similar sizes ranging between 73 and $86 \mathrm{~nm}$. Presentation of pVTK and BP on micelles surface did not significantly change in micelles size as it ranged between 59 and $80 \mathrm{~nm}$ and 74and $89 \mathrm{~nm}$ for pVTK- and BP-conjugated micelles, respectively (Figure 4A). Results also show that the average zeta potential for nonconjugated micelles ranged between -42 and $-54 \mathrm{mV}$. Both pVTK- and BP-conjugated micelles displayed a similar negative surface charge indicated by zeta potential of -14 to -60 $\mathrm{mV}$ and -31 to $-38 \mathrm{mV}$, respectively (Figure 4B). Given that the size of the sinusoidal gap in normal vasculature supplying the bone is < 80nm [56], pVTK- and BP-conjugated micelles are poised to utilize the leaky tumor vasculature with an average pore size of $200-600 \mathrm{~nm}$ to diffuse and preferentially accumulate in the tumor tissue [57]. Based on established reports $[50,58,59]$, the dense packing of the PEG brush and the presentation of negatively charged targeting ligands will minimize micelles interaction with blood proteins, platelets, and RBCs, which will increase their hemocompatibility and minimize their clearance by the reticular endothelial system in vivo. 
(A)

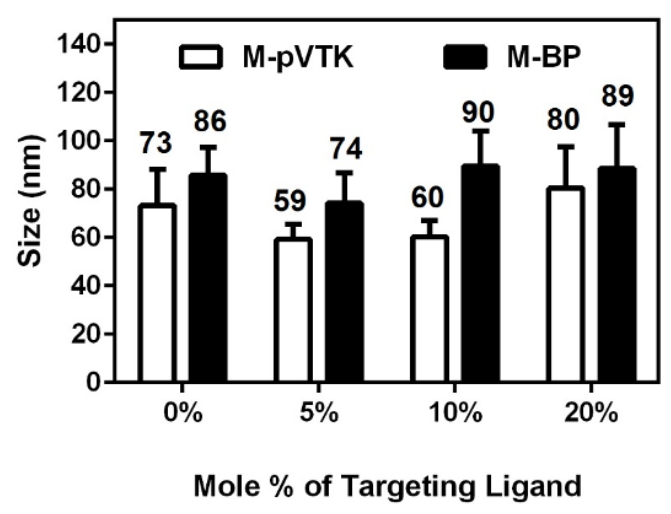

(B)

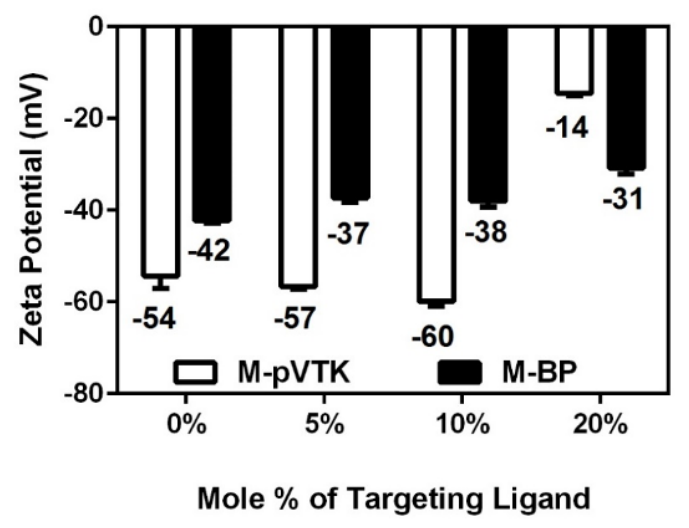

Figure 4. (A) Size and (B) zeta-potential characterization of 0, 5, 10, 20\% targeting ligand M-pVTK and M-BP particles. Results show the average + standard error of the mean (SEM) of three independent solutions for each micelle formulation.

\section{Binding of pVTK- and BP-conjugated micelles to bone-like surfaces}

Differential and extended binding of conjugated micelles to actively mineralizing bone surface in metastatic prostate cancer lesions is a critical motivation for selecting $\mathrm{pVTK}$ and BP as targeting ligands. Therefore, we investigated the binding of pVTK- and BPconjugated micelles to hydroxyapatite (HA), bone powder, and bone chips at different densities of the targeting ligands per micelle the ideal molar ratio needed for effective binding. Earlier reports show that free pVTK peptide utilizes phosphorylated groups to tightly bind to HA surfaces[45, 46, 53]. Therefore, we investigated whether covalent attachment of pVTK peptide to the PEG end of the PMMA- $b$ PAA- $b$-PEG polymer will negatively impact its binding to HA surface by comparing the binding of FITC-labeled free pVTK to that of FITC-labeled PMMA- $b$-PAA- $b$-PEG-pVTK polymer. Results show that $64 \%$ of free $\mathrm{pVTK}$ FITC peptide binds to HA surface upon incubation for $3 \mathrm{~h}$ at $37^{\circ} \mathrm{C}$, similar to the $63 \%$ binding observed with observed PMMA- $b$ PAA- $b$-PEG-pVTK-FITC (Figure 5A). Further, the binding isotherms of free pVTKFITC peptide and PMMA- $b$-PAA- $b$-PEGpVTK-FITC polymer were calculated and found 27.16 and $26.40 \mu \mathrm{M}$, respectively. These results indicate that the pVTK peptide presented on the surface of the micelle is as efficient as free pVTK in binding to the HA surface without any significant statistical differences.
We compared the binding of pVTK- and BPconjugated micelles to rat bone powder at $5 \%$, $10 \%$, and $20 \%$ (mole $\%$ of targeting ligand) at different ligands concentrations. Results show that pVTK-conjugated micelles exhibit similar binding to rat bone powder regardless of the mole $\%$ of the pVTK targeting ligand in the concentration range of $0.1-10 \mathrm{nM}$ (Figure 5B). In addition, we investigated the binding of pVTK-conjugated micelles to HA discs, which have dramatically lower surface area compared to rat bone powder, to determine whether the lack of discrimination between different micelles is based on the pVTK content is a result of the binding surface area. Results show that all pVTK-conjugated micelles exhibited similar binding $(63 \%)$ to the HA disc despite the apparent self-quenching of the FITC signal observed with micelles containing $20 \%$ pVTK ligands due to steric packing (Figure $5 \mathrm{C}$ ). We utilized pVTK-conjugated micelles with $10 \%$ pVTK ligands based on these findings in all subsequent studies. In comparison, BPconjugated micelles showed that micelles with $10 \%$ and $20 \%$ BP targeting ligands exhibit statistically higher binding to rat bone powder compared to micelles incorporated with only $5 \%$ of the targeting ligand (Figure 5D).

Cellular uptake of pVTK- and BPconjugated micelles

We investigated the uptake of conjugated micelles by the metastatic PC-3 and C4-2B prostate cancer cells, representing osteolytic 
(A)

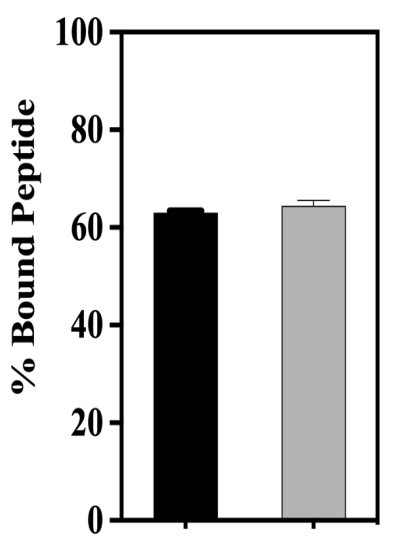

(C)

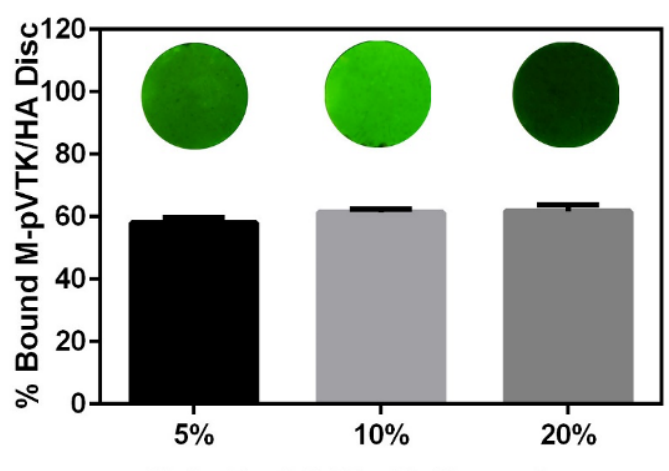

Mole \% of ABC-pVTK copolymer
(B)

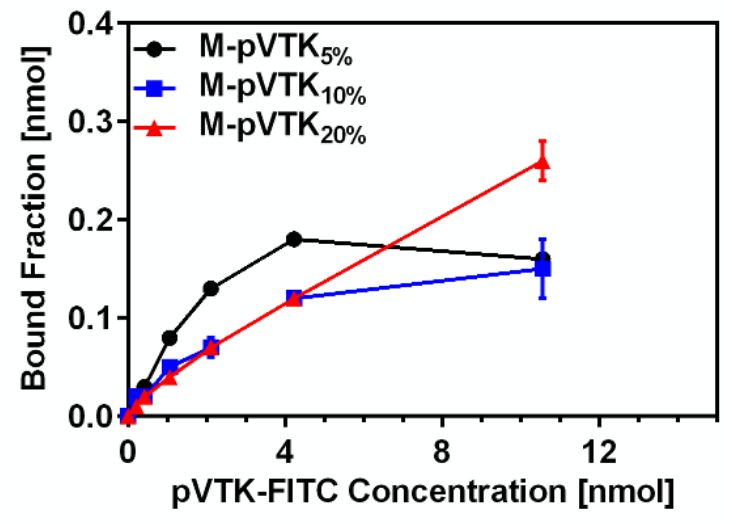

(D)

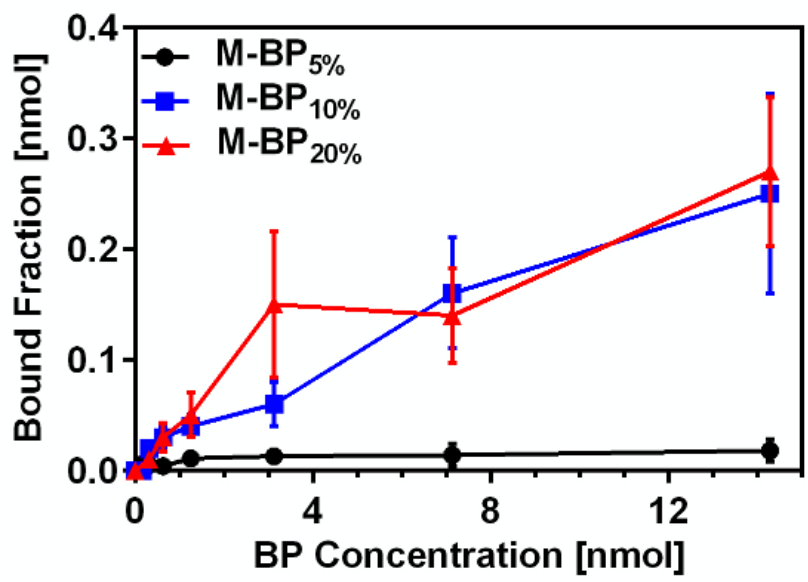

Figure 5. Binding of the particles to bone powder. (A) The percentage of pVTK-FITC peptide (left) and pVTK-FITC coupled PMMA-b-PAA-b-PEG triblock copolymer (right) bound on HA powder (B) M-pVTK binding kinetics, (C) M-BP binding kinetics, and (D) 5, 10,20\% mole of pVTK targeting particle binding to HA disk and the fluorescence images of these disks after pVTK targeting particle binding. Results show the average + SEM of three independent solutions for each bone conjugated particle formulation.

and mixed osteolytic / osteoblastic characteristics. We also investigated the ability of conjugated particles to discriminate between cancer and bone cells by evaluating their uptake into pre-osteoblast MC3T3, pre-osteoclast RAW 264.7, and RANKL activated RAW 264.7 cells. Cancer and bone cells were cultured in conventional tissue culture plates and on BLS to assess whether the interaction with the supporting environment will affect the cellular uptake processes.

Results show that $\mathrm{pVTK}$-conjugated and nonconjugated micelles exhibit higher uptake into PC-3 than their uptake into C4-2B cells when cultured on conventional tissue culture plates, but there was no difference in the uptake of both cell lines when cultured on BLS (Figure 6A). In comparison, M-pVTK $10 \%$ micelles exhibited statistically higher $(\mathrm{p}<0.5)$ uptake $(95 \%$ labeling) into MC3T3 cells cultured on tissue culture plates compared to non-conjugated micelles, which stained only $86 \%$ of the cell population. The same trend was observed upon culturing MC3T3 cells on BLS, where M$\mathrm{pVTK}_{10 \%}$ micelles exhibited statistically higher $(p<0.01)$ than non-conjugated micelles. Similarly, M-pVTK $10 \%$ micelles were internalized by a statistically higher fraction of RAW 264.7 and RANKL-activated RAW 264.7 cells compared to non-conjugated micelles (Figure 6A). 

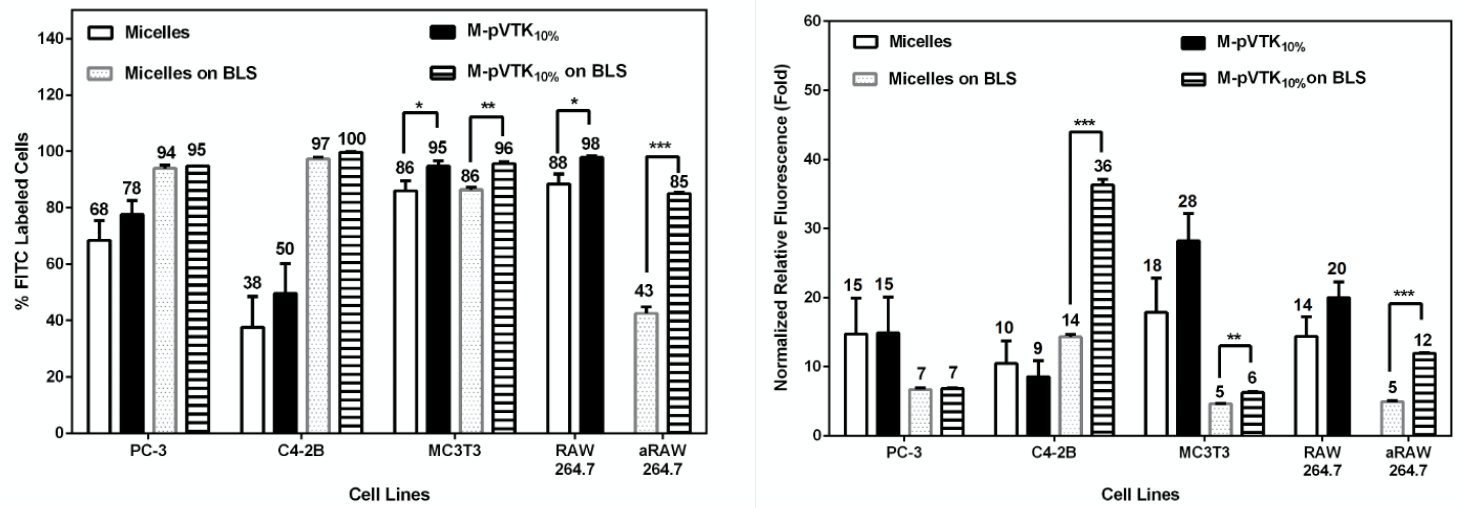

Figure 6. Prostate and bone cells uptake the particles from regular cell culture plates and BLS. The cells were first seeded on the plate. After $24 \mathrm{~h}$ the particles are added to the top of the cells and incubated for $3 \mathrm{~h}$. (A) M-pVTK $10 \%$ cell label, (B) Normalized mean fluorescence of FITC labeled cells. Results are the average of at least nine triplicate experiments + SEM samples. Percentage of labeled cells and normalized mean fluorescence increased by M-pVTK10\% were compared to FITC label non-conjugated micelles using a two-tailed Student-test where $*$ denotes $P<0.05$, and $* * *$ denotes $* * * P<0.001$.

Further, normalizing the intensity of intracellular fluorescence in different cell lines to that of untreated cells allowed quantitative comparison of intracellular concentration of different micelles. Results show that $\mathrm{M}$ $\mathrm{pVTK}_{10 \%}$ micelles exhibited statistically higher $(p<0.01)$ internalization into $C 4-2 B$ cells cultured on BLSs compared to non-conjugated micelles (Figure 6B). In addition, M-pVTK $10 \%$ micelles statistically higher intracellular concentration in MC3T3 cells $(\mathrm{p}<0.01)$ and RANKL-activated RAW 264.7 cells $(\mathrm{p}<0.01)$ cells compared to non-conjugated micelles. The ability of M-pVTK $10 \%$ micelles to preferentially bind and internalize into C4-2B, MC3T3, and activated RAW 264.7 cells, especially when in contact with BLS, indicates that the pVTKconjugated micelles will interact with both prostate cancer and bone cells and may be used for conjugated drug delivery to the epithelial and stromal compartments in metastatic prostate cancer lesions in bone.

In the second part of bone-conjugated particle uptake of prostate cancer cells and bone cells, we evaluated the effect of BP targeting ligand on the internalization of FITC-labeled BP particles as a function of BP density $(5,10$, and $20 \%$ BP particles) both in regular cell culture plate and BLS. We then compared them to nonconjugated particles following the same procedure of pVTK particles. The results show that $91 \%, 88 \%, 89 \%$, and $88 \%$ of PC-3 cells; $75 \%, 71 \%, 75 \%$, and $73 \%$ of $C 4-2 \mathrm{~B}$ cells; $96 \%$, $89 \%, 94 \%$, and $90 \%$ of MC3T3; and $97 \%, 98 \%$, $99 \%$, and $99 \%$ of RAW 264.7 cells were labeled by the FITC tagged non-conjugated, M-
$\mathrm{BP}_{5 \%}, \mathrm{M}-\mathrm{BP}_{10 \%}$, and $\mathrm{M}-\mathrm{BP}_{20 \%}$ particles, respectively (Figure 7A). Moreover, for all particles, the normalized relative FITC fluorescence values for PC-3, C4-2B, and MC3T3 were around 6, 5, and 9-fold, respectively. There was no statistical difference between non-conjugated particles and the BP targeting particles in these cell lines. However, increasing the BP density $5 \%, 10 \%$, and $20 \%$ of bone-conjugated particles in RAW 264.7 macrophage cells increased the normalized relative FITC fluorescence values $17-(\mathrm{p}<0.05)$, 23- $(\mathrm{p}<0.001)$, and 57-fold $(\mathrm{p}<0.001)$ compared to 14-fold increase of non-conjugated particles, respectively as seen in (Figure 7B). This higher relative internalization by macrophage trend is supported by earlier reports that showed that negatively charged particles and BPs or BPdecorated particles could target scavenger receptors on the cell membrane of macrophages cells. $[60,61]$. This result indicates BPdecorated bone-conjugated particles can target macrophages. Since the highest relative fluorescence was measured with the $20 \%$ BP particle formulation, we preferred to use this particle in further cellular experiments.

Finally, we designed a second BLS experiment to explore the $\mathrm{M}-\mathrm{BP}_{20 \%}$ particles uptake by seeding prostate cancer cells (PC-3 or C4-2B cells), or bone cells (MC3T3 or RANKL activated RAW 264.7 cells), on BLS and incubated for $24 \mathrm{~h}$ and followed the same pVTK-conjugated particle cellular uptake procedures. FITC-labeled PC-3 cells were 94\% and $91 \%$ after incubating with non-conjugated and $\mathrm{M}-\mathrm{BP}_{20 \%}$ particles, respectively. A similar 
trend was observed for C4-2B cells. Specifically, $97 \%$ and $94 \%$ of these cells were labeled with non-conjugated and M-BP20\% particles. Moreover, $86 \%$ and $86 \%$ of MC3T3, and $43 \%$ and $30 \%(p<0.01)$ of RAW 264.7 cells were labeled by the non-conjugated and $\mathrm{M}$ $\mathrm{BP}_{20 \%}$ particles, respectively (Figure 7C). Furthermore, the relative fluorescence intensity of FITC-labeled cells results shows that 7 and 6-fold increased fluorescence intensity in PC-3 cells; $14-$ and a 12-fold increase in C4-2B cells; 5- and 5-fold increase in MC3T3; and 5-, and 4fold increase in RAW 264.7 cells by the FITCtagged non-conjugated, and $\mathrm{M}-\mathrm{BP}_{20} \%$ particles, respectively (Figure 7D).

When Figures 6 and 7 are compared in general cellular labeling or fluorescence intensity fold increase, it is clear that bone-conjugated particle internalization through cancer and bone cells act differently because of the presence of BLS. For instance, PC-3 cells can be labeled about $90 \%$ when the cells are attached to the surface in the absence of BLS. In another prostate cancer cell line, C4-2B, a mixed form (osteoblastic and osteolytic character) of bone metastasis cells, particles will internalize less when compared with PC-3 on a regular tissue culture plate. These particle internalization rates are similar to our previous published study.[15] However, under the same experimental conditions with BLS (Figure 6), the particle internalization rates increase to more than $90 \%$, and pVTK bone-conjugated particles can label $100 \%$ with a maximum of 36-folds relative fluorescence intensity increase. The higher pVTK bone-conjugated particle uptake profile of the C4-2B cell line could be its osteoblast-like phenotype capable of mineralization with the production of bone surface alkaline phosphatase osteocalcin, osteonectin, bone sialoprotein, and osteoprotegerin [62, 63]. Most importantly, the C4-2B cells produced hydroxyapatite mineral in vitro. This in vitro hydroxyapatite mineral production could raise up the pVTK-bone conjugated particle affinity [64].

The MC3T3 cell line is a mouse osteoblast cell. Therefore, we also tested the pVTK and $\mathrm{BP}$ bone-conjugated particles in MC3T3 cells using a methodology similar to the tumor cells.
The initial tests with particles in medium incubated in tissue culture plates show that both bone-conjugated particles have a high cellular internalization rate $(\sim 90 \%)$. However, pVTKparticles achieve the highest statistically different cellular labeling with $95 \%$ and 28 folds relative intracellular fluorescence increase, as seen in Figure 6. However, in the case of cells on BLS and particles added afterward in medium, we observe higher internalization rates for all particle formulations. pVTK bone-conjugated particles have the highest MC3T3 cellular labeling with $96 \%$ and an increase in intracellular normalized fluorescence intensity by 6-folds (Figure 6). These results clearly show that pVTK particles can be internalized by osteoblasts. Further, pVTK is a well-characterized peptide formulation that can adsorb to the apatite surface and inhibits the mineralization in preosteoblastic cells with a dose-dependent response [47]. Because of the direct interaction of pVTK with mineralized surface or cells, pVTK particles are preferentially internalized by MC3T3 and C4-2B cells

Lastly, we investigated the bone-conjugated particles uptake interactions in RAW 264.7 macrophage cells on a regular tissue culture plate and RANKL-activated RAW 264.7 cells to osteoclasts on the BLS. Macrophage cells are capable of phagocytosis, which means they inherently internalize more particles than other cell lines. In the literature, negatively-charged particles and BP-conjugated particles are recognized by macrophages and tumoractivated macrophages (TAMs), which form approximately half of the tumor mass [65]. Many studies denote that TAMs contribute to drug resistance [66], and an elevated number of TAMs are correlated with therapy failure and poor diagnosis [67, 68]. Therefore, direct effects on these cells in the tumor microenvironment could contribute to the treatment of bone metastasis [69]. Our results confirm the high affinity between macrophages, and both bone-conjugated particles can label RAW 264.7 cells almost $100 \%$ (Figure $7 \mathrm{~A}$ ). 
(A)

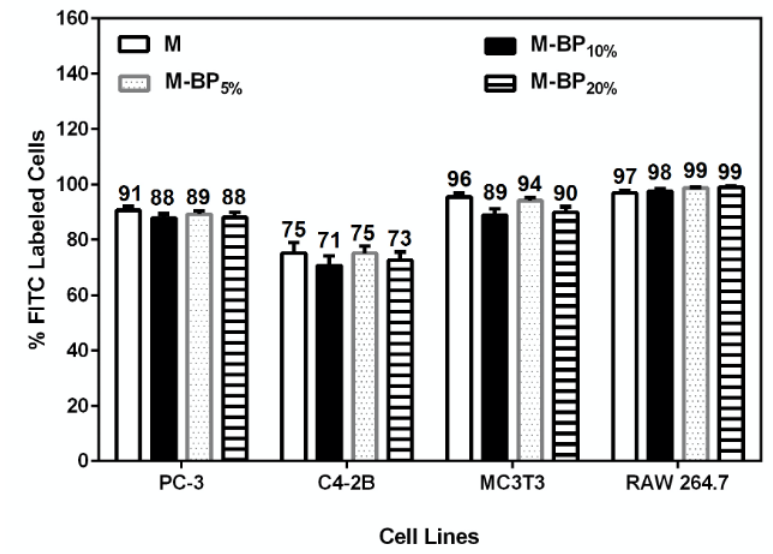

(C)

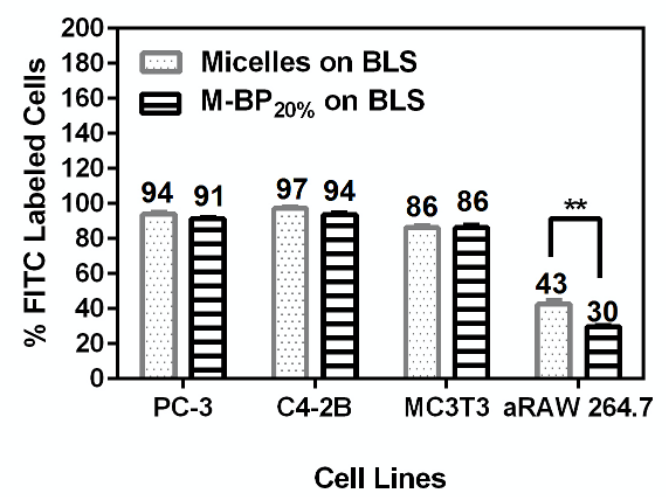

(B)

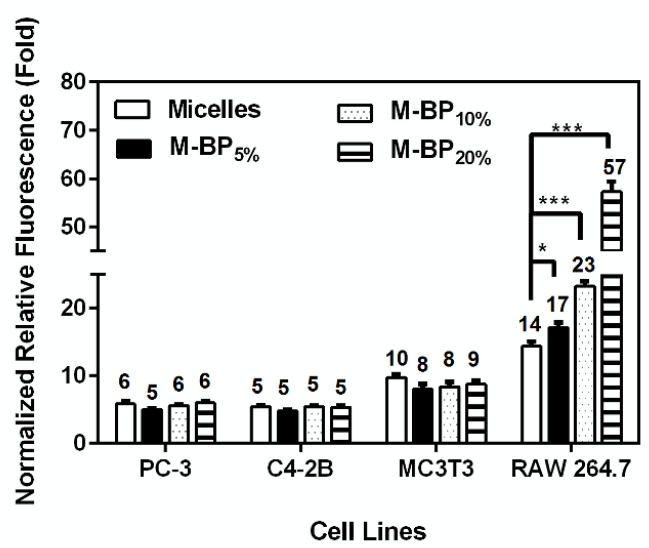

(D)

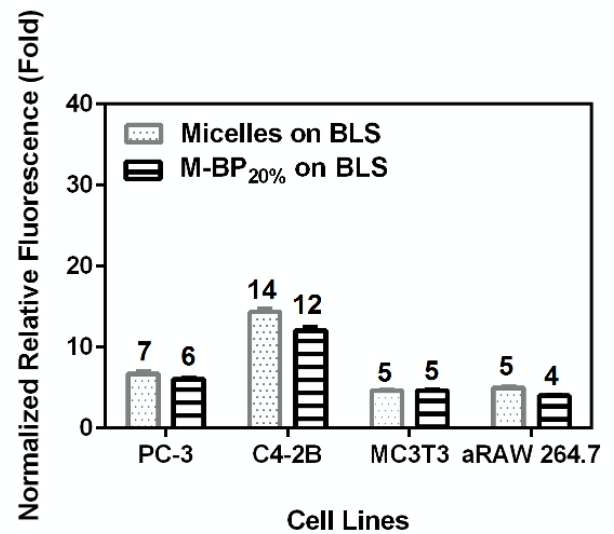

Figure 7. Prostate and bone cells uptake the particles from regular cell culture plates and BLS. The cells were first seeded on the plate. After $24 \mathrm{~h}$, the particles are added to the top of the cells and incubated for $3 \mathrm{~h}$. (A) FITC-label non-conjugated Micelles, $M-B P_{5 \%}, M-B P_{10 \%}$, and $M-B P_{20 \%}$, percent cell label on regular cell culture plates, (B) Normalized mean fluorescence of cells treated with FITC-label non-conjugated micelles, MI-BP $P_{5 \%}, M I-B P_{10 \%}$, and MI-BP $20 \%$ on regular cell culture plates. (C) FITC-label non-conjugated micelles, and MI-BP $20 \%$ cell label on BLS, (D) Normalized mean fluorescence of cells treated with FITC-label non-conjugated micelles $M-B P_{20 \%}$ on BLS. Percentage of labeled the cells and normalized mean fluorescence increase by fluorescently-label particles were compared to FITC label non-conjugated micelles using a two-tailed student's-test where ** denotes $P<0.01$.

Furthermore, increasing the number of BP targeting ligands displayed on the particles, the relative fluorescence intensity increases up to 57-folds (Figure 7B). Therefore, by increasing the number of BP on the particle, these particle formulations can be used to deliver specific agents to macrophages or TAMs. Interestingly, when RAW 264.7 cells are differentiated with RANKL on the BLS, we do not see higher internalization of BP-conjugated particles compared to other particle formulations. Also, it is important that ruffled bordered macrophages are indicative of osteoclasts activation and subsequent bone resorption with acidic enzymes. The lack of inability to form ruffled borders might affect the BP-particle uptake profile. This might be a mandatory effect in Figure 7 that the cells are first seeded and followed by particle incubation with the cells. Because of unable to form a ruffled border in osteoclasts treated with BP targeting particles, the labeled cells are the lowest with $30 \%$ between all particles. Furthermore, inhibition of ruffled border formations by BPtargeting particles as well as loading with an anticancer agent might have a synergistic effect in the treatment of bone metastasis. Whereas, as seen in Figure 6, pVTK-conjugated particles have the highest osteoclast uptake with the percentage of $85 \%$ and 12-fold normalized relative fluorescence increase.

Taking these cellular uptake results together, we can conclude that if bone metastasized cells are in osteolytic form (like PC-3 cells), BP- 
based targeting ligands are the ideal strategy to target cancer cells and TAMs. On the other hand, if the metastasized bone tumor is in a mixed format of both osteoblastic and osteolytic characteristics (like C4-2B cells), pVTK-targeting ligands are the preferred strategy for drug delivery.

\section{Cytotoxicity of CTX-loaded micelles}

To test the therapeutic effect of the boneconjugated particles, we loaded CTX as a model anticancer agent in the core of the particles using our established drug encapsulation protocol [15]. The CTX loading content was measured in non-conjugated M-pVTK $10 \%$ and $\mathrm{M}-\mathrm{BP}_{20}$ particles by HPLC. The loading efficiency was calculated based on a concentration versus CTX absorbance calibration curve. Results show that encapsulation efficiencies of CTX in non-conjugated particles, $\mathrm{M}-\mathrm{pVTK} \mathrm{VT}_{10 \%}$, and $\mathrm{M}-\mathrm{BP}_{20 \%}$ particles were $30.03 \pm 1.31 \%$, $32.33 \pm 4.87 \%$, and $32.23 \pm 4.75 \%$, respectively. Our reference study determined the CTX $\mathrm{IC}_{50}$ values of free and CTX-loaded particles in $\mathrm{PC}-3$ and $\mathrm{C} 4-2 \mathrm{~B}$ cells between 0.6 and $5.0 \mathrm{nM}$. Based on the established previous study and bone conjugated-particles cellular uptake experiments, we examined the therapeutic activity of these CTX-loaded particles at 0.1 , 1.0 , and $10 \mathrm{nM} \mathrm{CTX} \mathrm{concentrations} \mathrm{compared}$ to equal concentrations of free CTX for $48 \mathrm{~h}$ using resazurin cytotoxicity assay. We expected CTX-loaded bone-conjugated particles to exhibit a higher therapeutic effect since they can bind to the bone surface and higher particle internalization by cancer cells based on the type of targeting ligands. Results show the percentage of surviving all cell types decreases with an increase in the concentration of CTX incubated with all cell lines (Figure 8).

CTX-loaded non-conjugated particles exhibited the highest survival percentage between all concentrations and all cell lines on BLS compared with free CTX and pVTK- and BP- conjugated particles. This higher survival rate is because all cell lines can internalize free CTX via diffusion mechanism, boneconjugated particles can be adsorbed on BLS, leading to likely increased particles contact to the cells and more particle internalization with bone-targeting ligands. Once each cell line is evaluated with the highest treated CTX concentration with details, PC-3 cell survival was $60 \%, 83 \%(p<0.001), 78 \%(p<0.001)$, and
$66 \%(\mathrm{p}<0.05)$ with the treatment of free CTX, CTX-M, CTX-M-pVTK $10 \%$, and CTX-M$\mathrm{BP}_{20 \%}$, respectively (Figure 8A). BP boneconjugated particles display the lowest survival rate compared to CTX-loaded particle formulations. The higher therapeutic effect could be due to BP-conjugated particles having higher PC-3 cell uptake, and BP has an anticancer effect. C4-2B cell viability percentages treated with free CTX, CTX-M, CTX-M-pVTK $10 \%$, and CTX-M-BP $20 \%$, are $41 \%, 70(\mathrm{p}<0.001), 42 \%$, and $54 \%(\mathrm{p}<0.001)$, respectively (Figure 8B). CTX-loaded M$\mathrm{pVTK}_{10 \%}$ shows an overall similar cytotoxicity percentage to free CTX. This enhanced therapeutic effect could result from the pVTK targeting motive, which gains specific internalization of M-pVTK particles by C4-2B. The survival rates of MC3T3 cells after treating with free CTX, CTX-M, CTX-M-pVTK $10 \%$, and CTX-M-BP $20 \%$, are $80 \%, 90 \%(\mathrm{p}<0.001)$, $79 \%$, and $85 \%(\mathrm{p}<0.05)$, respectively (Figure $8 \mathrm{C})$. MC3T3 has higher survival rates with all CTX concentrations compared with all other cell lines because the model drug, CTX, can target epithelial cell lines such as prostate cancer cells but has no direct effect on osteoblasts. Because of the affinity of pVTKconjugated particles towards MC3T3 cells, the lowest viability rate is obtained by CTX-M$\mathrm{pVTK}_{10 \%}$. The treatment of RAW 264.7 macrophage cells with free CTX, CTX-M, CTX-M-pVTK $10 \%$, and CTX-M-BP $20 \%$, exhibit $52 \%, 93 \%(\mathrm{p}<0.001), 66 \%(\mathrm{p}<0.001)$, and $56 \%$ survival rates, respectively (Figure $8 \mathrm{D}$ ). We found that $\mathrm{M}-\mathrm{BP}_{20} \%$ particles have the highest total fluorescence in RAW 264.7 cells, indicating a higher BP bone-conjugated particle uptake profile than other particle formulations. Because of higher particle internalization, CTX-loaded ${\mathrm{M}-\mathrm{BP}_{20} \%}_{\text {shows a higher }}$ therapeutic effect than other formulations. Lastly, RANKL activated RAW 264.7 cells were treated with the same therapeutics -free CTX, CTX-M, CTX-M-pVTK $10 \%$, and CTX$\mathrm{M}-\mathrm{BP}_{20 \%}$ - showing $72 \%, 82 \%, 73 \%$, and $67 \%$ cell viability without statistical difference compared to free CTX (Figure 8E). However, the lowest viability is acquired with the treatment of CTX-loaded $\mathrm{M}-\mathrm{BP}_{20 \%}$ particles, which is statistically different compared to CTX-loaded non-conjugated particles $(\mathrm{p}<$ $0.01)$. 
(A)

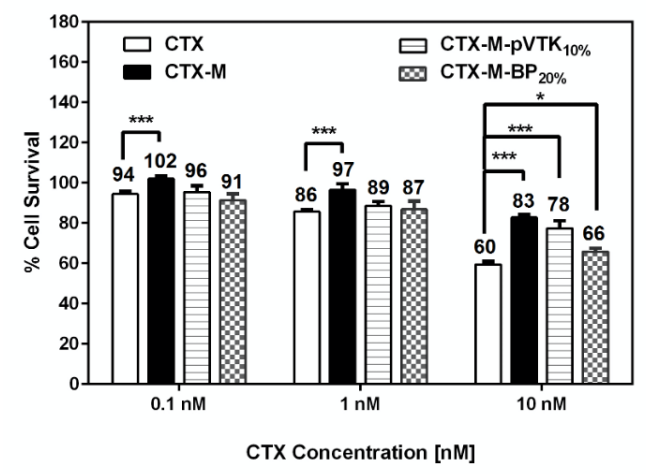

(B)

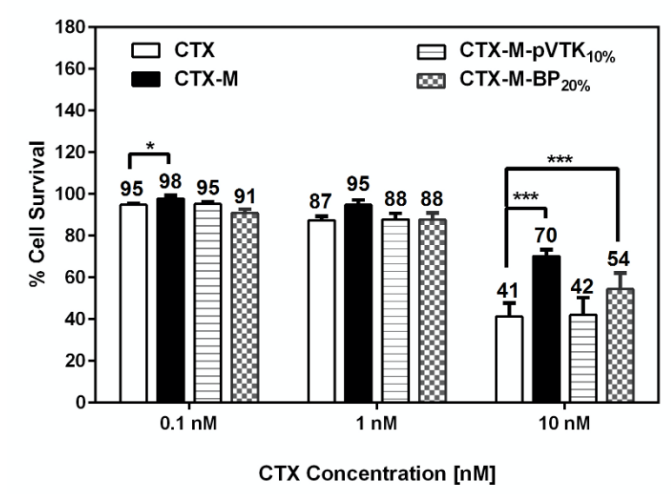

(C)

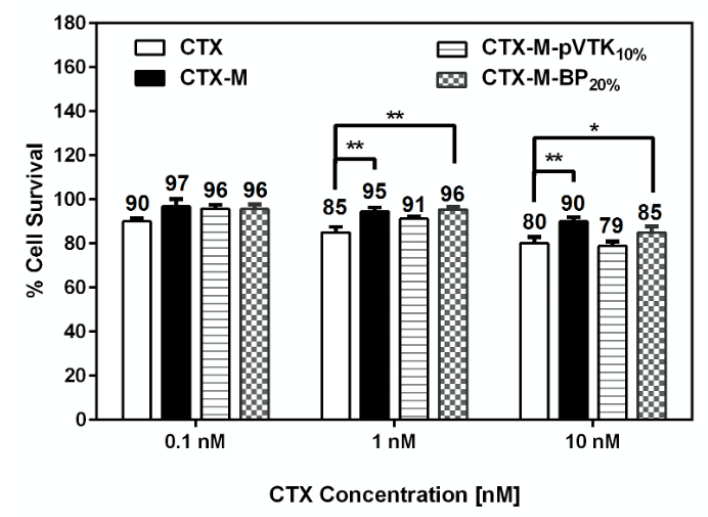

(D)

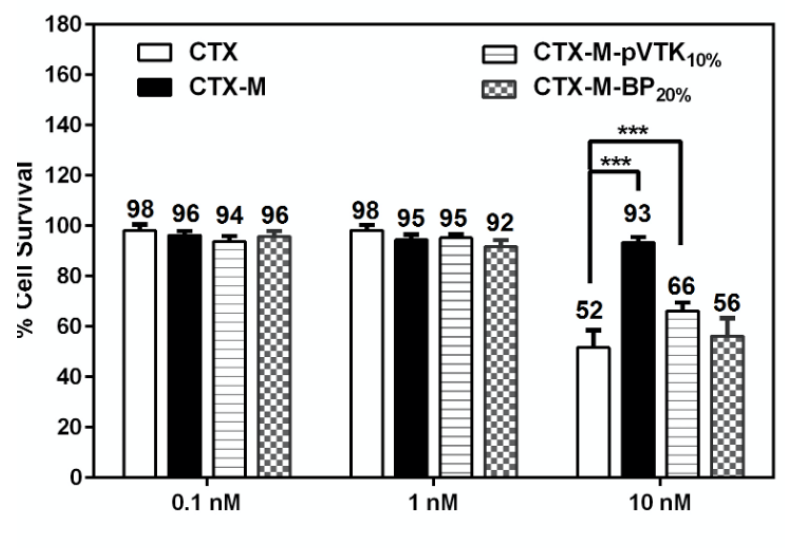

CTX Concentration [nM]

$(E)$

(E)

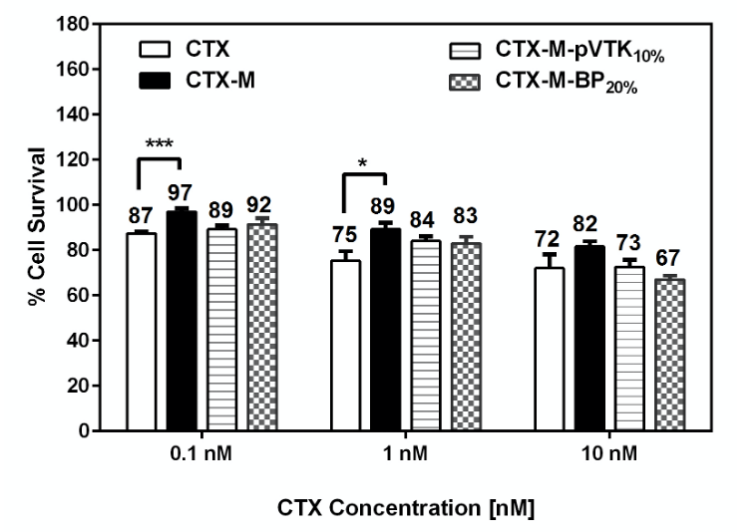

Figure 8. Therapeutic activity of CTX and CTX-loaded particles in prostate and bone cells on BLS. (A) PC-3, (B) C4-2B, (C) MC3T3, (D) RAW 264.7, and (E) RANKL activated RAW 264.7. The resazurin viability assay results of treated cells that normalized with untreated cells. Results are the average of triplicate experiments + SEM. Percentage of cell viability was compared to untreated cells using a two-tailed Student's t-test where *denotes $P<0.05$, ** denotes $P<0.01$, and *** denotes $P<0.001$.

In summary, we have shown that it is possible to efficiently deliver CTX-loaded boneconjugated particles to the bone. Although CTX is only a model anticancer drug, other therapeutics could also be chosen from various options such as antibodies, cytokines, proteins, or other anticancer agents with the proper boneconjugated strategy to inhibit a specific cell line and, at the same time, the crosstalk between bone and cancer cells. By findings from this invitro study will determine to pursue in vivo studies in progress such as based on the type of metastatic cancer cells, the most effective targeted nanomedicine tools will be decided. Both bone-bound particles might be used with in-vivo imaging modalities as a molecular 
probe to understand the type of the metastatic lesion. These targeting strategies will open new ways in combination therapy, which provides a more efficient and higher therapeutic effect on bone metastasis.

\section{Conclusions}

We have successfully synthesized two different bone-conjugated pVTK-peptide and BP-decorated triblock amphiphilic copolymers via atom transfer radical polymerization (ATRP) and "click" reactions. These copolymers self-assemble in an aqueous environment and form 60-90 nm size micelles with $\mathrm{pH}$ sensitive crosslinking shells as a function of bone-conjugated block densities. The results show that pVTK and BP decorated particles could bind to bone HA surface. pVTK bone-conjugated particles exhibited preferential uptake into C4-2B prostate cancer cells and osteoblasts on the BLS. Furthermore, whereas BP bone-conjugated particles were internalized preferentially by RAW 264.7 macrophage cells in regular tissue culture plates, PC-3 cells internalized these particles higher than other cell lines on BLS. This cellular uptake difference on BLS reveals insights into personalized medicine for treating bone metastasis based on the metastasis type, either osteoblastic, osteolytic, or mixed form.

Further, these bone conjugated particles could encapsulate Cabazitaxel, an anticancer agent, in the core with more than $30 \%$ drug-loading, enhancing the solubility and efficiency of a water-insoluble drug. Moreover, CTX-loaded bone conjugated particles showed a higher therapeutic effect in prostate cancer cells on the BLS than free CTX and CTX-loaded non-conjugated particle formulations. These results collectively indicate that $\mathrm{pVTK}$ and BP bone-targeting particles can potentially achieve selective delivery of anticancer agents into metastasized prostate cancer lesions in the bone. We will investigate these particles in vivo to assess the efficacy of targeting ligands to metastatic prostate cancer in bone.

\section{Acknowledgments}

Omer Aydin, Gopinath Tiruchinapally, and Ibrahim Youssef have contributed equally to this work. Omer Aydin did a portion of this work as part of his doctoral research in collaboration with I.Y. and G.T. under the supervision of M. ElSayed at the University of Michigan. G.T. led the design and synthesis of the polymers used in particles development while I.Y. and O.A. partnered both in particle characterization and in vitro assessment. The interdependence of their efforts and the equality of their roles led to the designation as equally contributing first authors.

Omer Aydin thanks the Fellowship from the National Ministry of Education of the Republic of Turkey (\#1416).

\section{Conflict of Interests}

The authors declare no conflicts of interest. For signed statements, please contact the journal office: editor@precisionnanomedicine.com

Quote this article as: Aydin O, Tiruchinapally G, Youssef I,, Ramaraju H, Durmaz YY, Kozloff KM, Kohn DH, and ElSayed MEH, Selective Binding of pVTK Peptide- and BisphosphonateFunctionalized Micelles to Prostate Cancer Cells, Osteoblasts, and Osteoclasts, Precis. Nanomed. 2022;5(1):851-869, https://doi.org/10.33218/001c.33142

\section{References}

1. Society AC. What are the key statistics about prostate cancer? : American Cancer Society; 2016 [updated 05/15/2016; cited 2013 May 28]. Available from:

http://www.cancer.org/cancer/prostatecancer/detailedguide/prostate-cancer-key-statistics.

2. McPhail S. SWPHO Briefing 4: Prostate cancer survival by stage. In: Health SWP, editor.: Cancer Analysis Team, South West Public Health Observatory; 2008.

3. Bubendorf L, Schopfer A, Wagner U, Sauter G, Moch H, Willi N, et al. Metastatic patterns of prostate cancer: an autopsy study of 1,589 patients. Hum Pathol. 2000;31(5):578-83.

4. Rana A, Chisholm GD, Khan M, Sekharjit SS, Merrick MV, Elton RA. Patterns of bone metastasis and their prognostic significance in patients with prostate carcinoma. Br J Urol. 1993;72(6):933-6. 
5. Paget S. Originally published as Volume 1, Issue 3421THE DISTRIBUTION OF SECONDARY GROWTHS IN CANCER OF THE BREAST. The Lancet. 1889;133(3421):571-3.

6. Ribatti D, Mangialardi G, Vacca A. Stephen Paget, and the 'seed and soil' theory of metastatic dissemination. Clin Exp Med. 2006;6(4):145-9.

7. Autio KA, Morris MJ. Targeting bone physiology for the treatment of metastatic prostate cancer. Clin Adv Hematol Oncol. 2013;11(3):134-43.

8. Low SA, Kopecek J. Targeting polymer therapeutics to the bone. Adv Drug Deliv Rev. 2012;64(12):1189-204.

9. Kingsley LA, Fournier PG, Chirgwin JM, Guise TA. Molecular biology of bone metastasis. Mol Cancer Ther. 2007;6(10):2609-17.

10. Keller ET, Brown J. Prostate cancer bone metastases promote both osteolytic and osteoblastic activity. J Cell Biochem. 2004;91(4):718-29.

11. Sottnik JL, Zhang J, Macoska JA, Keller ET. The PCa Tumor Microenvironment. Cancer Microenviron. 2011;4(3):283-97.

12. Kingsley LA, Fournier PGJ, Chirgwin JM, Guise TA. Molecular Biology of Bone Metastasis. American Association for Cancer Research. 2007;6(10):2609-17.

13. Clarke B. Normal bone anatomy and physiology. Clin J Am Soc Nephrol. 2008;3 Suppl 3:S1319.

14. Hendricks SB, Hill WL. The nature of bone and phosphate rock. Proc Natl Acad Sci U S A. 1950;36(12):731-7.

15. Aydin O, Youssef I, Yuksel Durmaz Y, Tiruchinapally G, ElSayed MEH. Formulation of AcidSensitive Micelles for Delivery of Cabazitaxel into Prostate Cancer Cells. Molecular pharmaceutics. 2016;13(4):1413-29.

16. Sumanasuriya S, De Bono J. Treatment of Advanced Prostate Cancer-A Review of Current Therapies and Future Promise. Cold Spring Harb Perspect Med. 2018;8(6).

17. Ebetino FH, Hogan AM, Sun S, Tsoumpra MK, Duan X, Triffitt JT, et al. The relationship between the chemistry and biological activity of the bisphosphonates. Bone. 2011;49(1):20-33.

18. Jakob T, Tesfamariam YM, Macherey S, Kuhr K, Adams A, Monsef I, et al. Bisphosphonates or RANK-ligand-inhibitors for men with prostate cancer and bone metastases: a network meta-analysis. Cochrane Database of Systematic Reviews. 2020(12).

19. Cotesta S, Jahnke W, Rondeau JM, Weiler S, Widler L. Phenylalkyl-imidazole-bisphosphonate compounds. Google Patents; 2011.

20. Takeuchi M, Sakamoto S, Kawamuki K, Kurihara H, Nakahara H, Isomura Y. Studies on novel bone resorption inhibitors. II. Synthesis and pharmacological activities of fused azaheteroarylbisphosphonate derivatives. Chem Pharm Bull (Tokyo). 1998;46(11):1703-9.

21. Weivoda MM, Oursler MJ. The Roles of Small GTPases in Osteoclast Biology. Orthop Muscular Syst. 2014;3.

22. Luckman SP, Hughes DE, Coxon FP, Russell RGG, Rogers MJ. Nitrogen-Containing Bisphosphonates Inhibit the Mevalonate Pathway and Prevent Post-Translational Prenylation of GTPBinding Proteins, Including Ras. Journal of Bone and Mineral Research. 1998;13(4):581-9.

23. Rogers MJ, Mönkkönen J, Munoz MA. Molecular mechanisms of action of bisphosphonates and new insights into their effects outside the skeleton. Bone. 2020;139:115493.

24. Clezardin P. Mechanisms of action of bisphosphonates in oncology: a scientific concept evolving from antiresorptive to anticancer activities. BoneKEy Rep. 2013;2.

25. Wood J, Bonjean K, Ruetz S, Bellahcene A, Devy L, Foidart JM, et al. Novel antiangiogenic effects of the bisphosphonate compound zoledronic acid. J Pharmacol Exp Ther. 2002;302(3):1055-61.

26. Molinuevo MS, Bruzzone L, Cortizo AM. Alendronate induces anti-migratory effects and inhibition of neutral phosphatases in UMR106 osteosarcoma cells. Eur J Pharmacol. 2007;562(1-2):2833. 
27. Ottewell PD, Monkkonen H, Jones M, Lefley DV, Coleman RE, Holen I. Antitumor effects of doxorubicin followed by zoledronic acid in a mouse model of breast cancer. J Natl Cancer Inst. 2008;100(16):1167-78.

28. Kim SJ, Uehara H, Yazici S, He J, Langley RR, Mathew P, et al. Modulation of bone microenvironment with zoledronate enhances the therapeutic effects of STI571 and paclitaxel against experimental bone metastasis of human prostate cancer. Cancer Res. 2005;65(9):3707-15.

29. Lu S, Zhang J, Zhou Z, Liao ML, He WZ, Zhou XY, et al. Synergistic inhibitory activity of zoledronate and paclitaxel on bone metastasis in nude mice. Oncol Rep. 2008;20(3):581-7.

30. Vordos D, Paule B, Vacherot F, Allory Y, Salomon L, Hoznek A, et al. Docetaxel and zoledronic acid in patients with metastatic hormone-refractory prostate cancer. BJU Int. 2004;94(4):524-7.

31. Zhong Y, Li S. New Progress in Improving the Delivery Methods of Bisphosphonates in the Treatment of Bone Tumors. Drug Des Devel Ther. 2021;15:4939-59.

32. Lin JH. Bisphosphonates: a review of their pharmacokinetic properties. Bone. 1996;18(2):75-85.

33. Israeli RS. Managing bone loss and bone metastases in prostate cancer patients: a focus on bisphosphonate therapy. Rev Urol. 2008;10(2):99-110.

34. Thompson K, Rogers MJ, Coxon FP, Crockett JC. Cytosolic entry of bisphosphonate drugs requires acidification of vesicles after fluid-phase endocytosis. Mol Pharmacol. 2006;69(5):1624-32.

35. So A, Chin J, Fleshner N, Saad F. Management of skeletal-related events in patients with advanced prostate cancer and bone metastases: Incorporating new agents into clinical practice. Can Urol Assoc J. 2012;6(6):465-70.

36. Meads MB, Hazlehurst LA, Dalton WS. The bone marrow microenvironment as a tumor sanctuary and contributor to drug resistance. Clin Cancer Res. 2008;14(9):2519-26.

37. Lipton A. New strategies to prevent and manage bone complications in cancer. Clinical advances in hematology \& oncology : H\&O. 2011;9(1):42-4.

38. Lipton A. Implications of bone metastases and the benefits of bone-targeted therapy. Semin Oncol. 2010;37 Suppl 2:S15-29.

39. Thamake SI, Raut SL, Gryczynski Z, Ranjan AP, Vishwanatha JK. Alendronate coated polylactic-co-glycolic acid (PLGA) nanoparticles for active targeting of metastatic breast cancer. Biomaterials. 2012;33(29):7164-73.

40. Crawford ED, Heidenreich A, Lawrentschuk N, Tombal B, Pompeo ACL, Mendoza-Valdes A, et al. Androgen-targeted therapy in men with prostate cancer: evolving practice and future considerations. Prostate Cancer and Prostatic Diseases. 2019;22(1):24-38.

41. Hsu WK, Virk MS, Feeley BT, Stout DB, Chatziioannou AF, Lieberman JR. Characterization of osteolytic, osteoblastic, and mixed lesions in a prostate cancer mouse model using $18 \mathrm{~F}-\mathrm{FDG}$ and $18 \mathrm{~F}-$ fluoride PET/CT. J Nucl Med. 2008;49(3):414-21.

42. Kaighn ME, Narayan KS, Ohnuki Y, Lechner JF, Jones LW. Establishment and characterization of a human prostatic carcinoma cell line (PC-3). Invest Urol. 1979;17(1):16-23.

43. Pfitzenmaier J, Quinn JE, Odman AM, Zhang J, Keller ET, Vessella RL, et al. Characterization of C4-2 Prostate Cancer Bone Metastases and Their Response to Castration. Journal of Bone and Mineral Research. 2003;18(10):1882-8.

44. Keller ET, Brown J. Prostate cancer bone metastases promote both osteolytic and osteoblastic activity. Journal of cellular biochemistry. 2004;91(4):718-29.

45. Segvich S, Biswas S, Becker U, Kohn DH. Identification of peptides with targeted adhesion to bone-like mineral via phage display and computational modeling. Cells Tissues Organs. 2009;189(14):245-51.

46. Segvich SJ, Smith HC, Kohn DH. The adsorption of preferential binding peptides to apatite-based materials. Biomaterials. 2009;30(7):1287-98.

47. Ramaswamy J, Nam HK, Ramaraju H, Hatch NE, Kohn DH. Inhibition of osteoblast mineralization by phosphorylated phage-derived apatite-specific peptide. Biomaterials. 2015;73:120-30. 
48. Kavand A, Anton N, Vandamme T, Serra CA, Chan-Seng D. Synthesis and functionalization of hyperbranched polymers for targeted drug delivery. Journal of Controlled Release. 2020;321:285-311.

49. Zhang S, Gangal G, Uludag H.' Magic bullets' for bone diseases: progress in rational design of bone-seeking medicinal agents. Chem Soc Rev. 2007;36(3):507-31.

50. Medina SH, Tiruchinapally G, Chevliakov MV, Durmaz YY, Stender RN, Ensminger WD, et al. Targeting hepatic cancer cells with pegylated dendrimers displaying N-acetylgalactosamine and SP94 peptide ligands. Adv Healthc Mater. 2013;2(10):1337-50.

51. Kozloff KM, Volakis LI, Marini JC, Caird MS. Near-infrared fluorescent probe traces bisphosphonate delivery and retention in vivo. J Bone Miner Res. 2010;25(8):1748-58.

52. Ramaraju H, Miller SJ, Kohn DH. Dual-functioning phage-derived peptides encourage human bone marrow cell-specific attachment to mineralized biomaterials. Connective Tissue Research. 2014;55(sup1):160-3.

53. Addison WN, Miller SJ, Ramaswamy J, Mansouri A, Kohn DH, McKee MD. Phosphorylationdependent mineral-type specificity for apatite-binding peptide sequences. Biomaterials. 2010;31(36):9422-30.

54. Russell PJ, Kingsley EA. Human prostate cancer cell lines. Methods Mol Med. 2003;81:21-39.

55. Dai J, Zhang H, Karatsinides A, Keller JM, Kozloff KM, Aftab DT, et al. Cabozantinib inhibits prostate cancer growth and prevents tumor-induced bone lesions. Clin Cancer Res. 2014;20(3):617-30.

56. Low SA, Kopecek J. Targeting polymer therapeutics to bone. Adv Drug Deliv Rev. 2012;64(12):1189-204.

57. Fang J, Nakamura H, Maeda H. The EPR effect: Unique features of tumor blood vessels for drug delivery, factors involved, and limitations and augmentation of the effect. Advanced drug delivery reviews. 2011;63(3):136-51.

58. Dobrovolskaia MA, Patri AK, Simak J, Hall JB, Semberova J, De Paoli Lacerda SH, et al. Nanoparticle size and surface charge determine effects of PAMAM dendrimers on human platelets in vitro. Molecular pharmaceutics. 2012;9(3):382-93.

59. Dobrovolskaia MA, Aggarwal P, Hall JB, McNeil SE. Preclinical studies to understand nanoparticle interaction with the immune system and its potential effects on nanoparticle biodistribution. Molecular pharmaceutics. 2008;5(4):487-95.

60. Stemmer U, Ramprecht C, Zenzmaier E, Stojcic B, Rechberger G, Kollroser M, et al. Uptake and protein targeting of fluorescent oxidized phospholipids in cultured RAW 264.7 macrophages. Biochim Biophys Acta. 2012;1821(4):706-18.

61. Kelly C, Jefferies C, Cryan SA. Targeted liposomal drug delivery to monocytes and macrophages. J Drug Deliv. 2011;2011:727241.

62. Muralidharan A, Smith MT. Pathobiology and management of prostate cancer-induced bone pain: recent insights and future treatments. Inflammopharmacology. 2013;21(5):339-63.

63. Jin JK, Dayyani F, Gallick GE. Steps in prostate cancer progression that lead to bone metastasis. Int J Cancer. 2011;128(11):2545-61.

64. Lin DL, Tarnowski CP, Zhang J, Dai J, Rohn E, Patel AH, et al. Bone metastatic LNCaPderivative C4-2B prostate cancer cell line mineralizes in vitro. Prostate. 2001;47(3):212-21.

65. Vinogradov S, Warren G, Wei X. Macrophages associated with tumors as potential targets and therapeutic intermediates. Nanomedicine (Lond). 2014;9(5):695-707.

66. Fischer C, Jonckx B, Mazzone M, Zacchigna S, Loges S, Pattarini L, et al. Anti-PlGF inhibits growth of $\operatorname{VEGF}(\mathrm{R})$-inhibitor-resistant tumors without affecting healthy vessels. Cell. 2007;131(3):463-75.

67. Steidl C, Lee T, Shah SP, Farinha P, Han G, Nayar T, et al. Tumor-associated macrophages and survival in classic Hodgkin's lymphoma. N Engl J Med. 2010;362(10):875-85.

68. Tang X, Mo C, Wang Y, Wei D, Xiao H. Anti-tumour strategies aiming to target tumourassociated macrophages. Immunology. 2013;138(2):93-104. 
69. Rogers TL, Holen I. Tumour macrophages as potential targets of bisphosphonates. J Transl Med. 2011;9:177. 